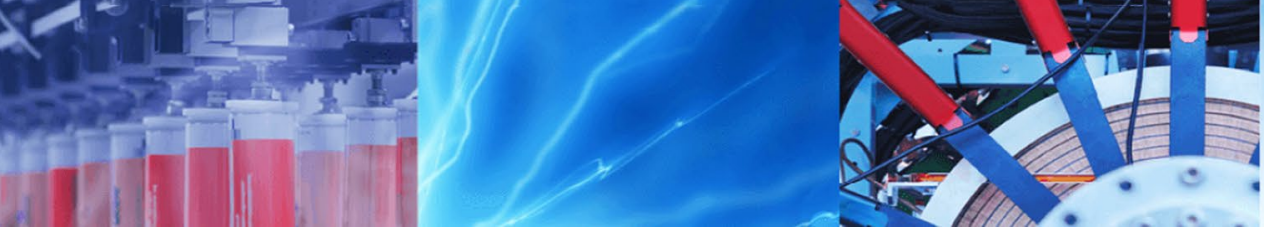

Research Article

\title{
Numerical simulation of dynamic fracture toughness tests: using RKR criterion
}

\author{
Jianhua Pan ${ }^{1,2}$. Mingjie Guo ${ }^{1}$
}

(c) Springer Nature Switzerland AG 2019

\begin{abstract}
This paper examines the numerical simulation on dynamic fracture toughness values derived from SHPB testing programs with three-point bending specimens using RKR criterion. Three-dimensional and two-dimensional finite element analyses are performed by using software ABAQUS and 3D fracture mechanics code ZENCRACK. The finite element model includes the bullet, incident bar, specimen and supports. Three-point bending specimens with different ratios values of initial crack lengths to width are utilized for the simulations under the identical initial conditions. The fracture initiation time is explored with the RKR local stress fracture criterion. The dynamic fracture toughness value of the material is determined by the combination of response curve of the dynamic stress intensity factor and fracture initiation time. The experimental data are taken as a benchmark to verify the results of three-dimensional and two-dimensional finite element computations. It is found that the computational results from 3D finite element are more accurate.
\end{abstract}

Keywords Dynamic fracture toughness · RKR criterion - Numerical simulation · Three-point bending specimen

\section{List of symbols}

A Cross-section area of the bar

a/W Length-to-width ratio

B Thickness of the specimen $(\mathrm{mm})$

b Width of the specimen ligament $(\mathrm{mm})$

C One-dimensional elastic wave velocity

DSIF Dynamic stress intensity factor

$d_{c} \quad$ Critical distance ahead of the crack tip $(\mu \mathrm{m})$

$\mathrm{E} \quad$ Elastic modulus of incident bar

$G_{l} \quad$ Elastic strain energy release rate

$J_{I}(t) \quad J$-integration from FEA computations

$K_{l} \quad$ Stress intensity factor $(\mathrm{MPa} \sqrt{\mathrm{m}})$

$K_{l d} \quad$ Dynamic stress intensity factor $(\mathrm{MPa} \sqrt{\mathrm{m}})$

$\dot{K}_{l} \quad$ Loading rate of dynamic test $(\mathrm{MPa} \sqrt{\mathrm{m}} / \mathrm{s})$

$L \quad$ Length of the specimen $(\mathrm{mm})$

$P_{i}(t) \quad$ Load value of SHPB

$S \quad$ Span of the specimen $(\mathrm{mm})$

SHPB Split Hopkinson pressure bar

SIF Stress intensity factor
TPB Three-point bending

$t_{f} \quad$ Crack initiation time $(\mu \mathrm{s})$

$V_{0} \quad$ Speed of cylindrical bullet $(\mathrm{m} / \mathrm{s})$

$u(t) \quad$ Displacement value of specimen at the contact-

ing position

W Width of the specimen $(\mathrm{mm})$

3D Three-dimensional

2D Two-dimensional

$v \quad$ Poisson's ratio

$\rho \quad$ Material density $\left(\mathrm{kg} / \mathrm{m}^{3}\right)$

$\varepsilon^{p l} \quad$ Equivalent strain

$\dot{\varepsilon}^{p l} \quad$ Strain rate

$\varepsilon_{i}(t) \quad$ Compression stress wave

$\varepsilon_{r}(t) \quad$ Stretching wave

$\sigma_{y} \quad$ Yield stress (MPa)

$\sigma_{y y} \quad$ Normal stress perpendicular to the crack surface (GPa)

\footnotetext{
$\triangle$ Jianhua Pan, panjianhua_123@163.com | ${ }^{1}$ State Key Laboratory of Nuclear Power Safety Monitoring Technology and Equipment, China Nuclear Power Engineering Co., Shenzhen 518172, China. ${ }^{2}$ School of Mechanical Engineering, Hefei University of Technology, Hefei 230009, China.
} 


\section{Introduction}

Dynamic fracture toughness value of material is an essential parameter for the assessment of pressure vessels and oil and gas pipelines, seismic design of structures and etc. Therefore, it is of great significance to study the dynamic fracture behavior of materials. The dynamic fracture issue with inertia and stress wave effects which cannot be ignored is mainly focused on.

Testing programs for dynamic fracture toughness of materials are not as well developed and standardized as those for static fracture toughness tests. Different methods are utilized to compute the dynamic fracture toughness values of materials. A procedure adopted widely is Charpy pendulum impact test. However, the maximum average loading rate $\dot{K}_{l}$ of Charpy tests can only get the attainment of $10^{5} \mathrm{MPa} \sqrt{\mathrm{m}} / \mathrm{s}$. Higher loading rates should require other devices, such as split Hopkinson pressure bar (SHPB) loading on pre-cracked three-point bending (TPB) specimens [1-4]. The basic principle of SHPB test program is as follows. The cylindrical bullet is pushed out at a certain speed $V_{0}$ using the compressed air gun. Then the compression stress wave $\varepsilon_{i}(t)$ is generated from hitting of the bullet and incident bar and propagating along the incident bar. This stress wave could be recorded by the strain gauge attached to surface of the bar. When the compression stress wave propagates to the interface of the TPB specimen and the incident bar, a part of energy passes through the specimen and the device supports while other part of energy returns to the incident bar as a stretching wave $\varepsilon_{r}(t)$, i.e. a reflection wave, recorded by the strain gauge. According to the one-dimensional stress wave theory expressed by Eqs. (1) and (2), the load $P_{i}(t)$ and corresponding displacement $u(t)$ can be calculated quantitatively as follows

$P_{i}(t)=E A\left(\varepsilon_{i}(t)+\varepsilon_{r}(t)\right)$

$u(t)=C \int_{0}^{t}\left(\varepsilon_{i}(t)-\varepsilon_{r}(t)\right) d \tau$

where $E$ denotes the elastic modulus of incident bar, $A$ represents the cross-sectional area of the bar, $C$ denotes the one-dimensional elastic wave velocity in the incident bar. The schematic diagram of the whole device is illustrated in Fig. 1.

It is difficult to get an analytical solution for this dynamic fracture problem due to the existing of inertial force. Even if the case is as simple as the model of three-point bending specimen, the exact analytical solution cannot be constructed easily. Only the approximate solution procedures $[5,6]$ can be performed, such as Kishimoto model and spring mass model. Therefore, the

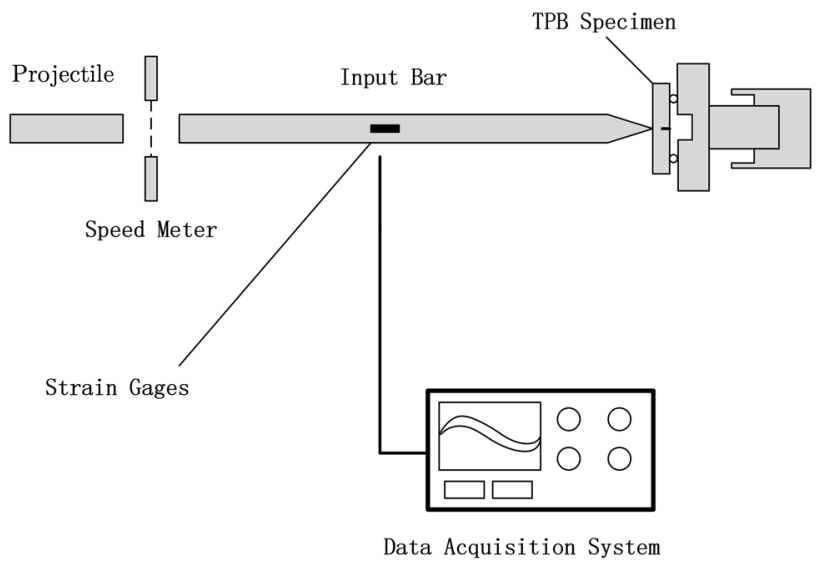

Fig. 1 Schematic diagram of SHPB testing program using TPB specimen

experiment-numerical methodology associated with finite element analysis has been employed in some research works to explore this problem. The split Hopkinson pressure bar (SHPB) technique was used to measure dynamic loads applied to a fatigue-precracked bend specimen. The dynamic stress intensity factor history for the bend specimen is evaluated by means of a dynamic finite element analysis [2-4, 7]. Ruibo et al. [8] revealed that the relationship between static loading stress intensity factor and crack opening displacement was also available for dynamic loading situations. There are a lot of research efforts on the computations of dynamic stress intensity factors using two-dimensional finite element analysis, but few with three-dimensional finite element computations. Some research works eliminated that $[2,9-11]$ the effects of three-dimensional on the stress intensity factor of precracked specimen were neglected in the two-dimensional analyse. It is usually infeasible to deal with the crack tip of the model in 3D finite element analysis. The three dimensionality of crack tip stress field and two dimensional near tip solutions are investigated in paper $[2,12]$. Their results exhibited that the plane-stress conditions prevail at distances form the crack tip greater than half the specimen thickness. A procedure was developed to estimate the stress intensity factor under dynamic loading conditions, in which the dynamic stress intensity factor is evaluated from static stress intensity factor and impact response function $[2,13]$. Hopkinson pressure bar has been extensively used for the measurement of the dynamic fracture toughness. The concepts and principles associated with SHPB are discussed for the measurement of dynamic fracture properties of materials. The propagation behavior of the time based loading and generation of stress wave has been explored using finite element method $[2,14,15]$.

It has been questioned that the simple treatment of crack tip in 3D finite element analysis where a large number of 
tetrahedral elements were utilized to mesh 00the crack tip. However, when multi-specimen numerical simulations are performed, the meshes of crack tip of all FEA models need to be identical. In this paper, ZENCRACK software [16] is used for implicit dynamic simulation of the model having deep cracks. The dynamic fracture mechanics of three-point bending specimens are computed. The local stress fracture criterion of RKR is employed to examine the initiation cracking times. In this paper, the two-dimensional plane strain finite element simulations are also carried out. The comparison between the results of two-dimensional and threedimensional finite element analyzes is conducted to study the effects of three-dimensional on dynamic stress intensity factors(DSIF)in the simulations.

\section{Numerical model}

In this paper, ABAQUS, a commercial finite element software [17], is employed to simulate the dynamic fracture test programs using three-point bending specimen. Some research [15] compared the J-integral results computed by ABAQUS solver and WARP3D which is also a famous software adopted in dynamic nonlinear fracture mechanics under dynamic loading. The results exhibited that they were in good agreement.

\subsection{Specimen geometry and material parameters}

The finite element model includes bullet, incident rod, specimen and supports. The diameter of the bullet and the incident bar is $22 \mathrm{~mm}$. The lengths of the bullet and incident bar are $330 \mathrm{~mm}$ and $1000 \mathrm{~mm}$ respectively. The contact condition between the incident bar and specimen is similar to the Charpy impact test. The specimen size is list as follows: length $L=100 \mathrm{~mm}$, width $\mathrm{W}=20 \mathrm{~mm}$, thickness $\mathrm{B}=10 \mathrm{~mm}$ and span $\mathrm{S}=80 \mathrm{~mm}$. They meet requirements recommended in the standard ASTM E1820-01 [18]. The ratio of initial crack length to specimen width is defined as $a / w$, which is taken on $0.3,0.5$ and 0.7 respectively. The value of the projectile impact speed $V_{0}$ is $10 \mathrm{~m} / \mathrm{s}$. Linear elastic material parameters are set for bullet, incident bar and supports due to the feature of SHPB test. The material parameters are as follows: elastic modulus $\mathrm{E}=200 \mathrm{GPa}$, poisson's ratio $v=0.3$ and material density $\rho=7850 \mathrm{~kg} / \mathrm{m}^{3}$. The specimen material is a type of aluminum alloy which has the material parameters: elastic modulus $\mathrm{E}=72 \mathrm{GPa}$, Poisson's ratio $v=0.3$ and material density $\rho=2800 \mathrm{~kg} / \mathrm{m}^{3}$. Bodner-Partom criterion is adopted for the constitutive equation in the material plastic flow stage. $\left\{\begin{array}{l}\bar{\sigma}=\bar{\sigma}_{0}\left(\varepsilon^{p l}\right) \cdot\left(1+\frac{\dot{\varepsilon}^{p l}}{D}\right)^{\frac{1}{m}} \\ \bar{\sigma}_{0}\left(\varepsilon^{p l}\right)=\sigma_{y}+k \cdot\left(\varepsilon^{p l}\right)^{n}\end{array}\right.$

where $\varepsilon^{p l}$ denotes the equivalent strain, $\dot{\varepsilon}^{p l}$ represents the strain rate. $D, m, n, k$ are material constant parameters. Relative parameters of aluminum alloy materials [19] are list in Table 1.

\subsection{Finite element model of the simulation}

Due to the symmetry of the model and boundary conditions, the 3D finite element analysis in this paper includes a quarter model of the bullet, incident bar and specimen, a half model of the supports. Finite element models of bullets, incident bars and supports are meshed with 8-node hexahedral element C3D8 in ABAQUS software. The stress wave is generated by the impact of bullet and incident bar. It is necessary to provide precisely mesh in parts stress wave propagated to ensure reasonable accuracy. The bullet part has 615 elements and 966 nodes. The incident bar model has 2080 elements and 3217 nodes. The support model has 320 elements and 468 nodes.

Specimen part of the model is meshed with 8-node hexahedral element C3D8. Then the crack tip region is proceeded with crack-block technology in ZENCRACK software. Crackblock is a group of elements consisted of hexahedral elements. ZENCRACK software maps the crack-block into the mesh at crack tip region of the model to replace the original standard hexahedral element in order to construct crack in the original finite element model having no crack. In this paper, crack-block type of s04_t $35 \times 1$ in the standard library of ZENCRACK is adopted, which is illustrated in Fig. 2. As long as the original hexahedral elements at the crack tip region have the same sizes, the meshes for the crack tip region processed by ZENCRACK will be completely identical for specimen models with various ratio values of a/W. This can avoid numerical simulation deviation due to the inconsistency of crack tip mesh of models having different crack length ratio values. The numbers of elements and nodes generated in the specimen models with three ratio values $(\mathrm{a} / \mathrm{W}=0.3$, $\mathrm{a} / \mathrm{W}=0.5, \mathrm{a} / \mathrm{W}=0.7$ ) are 5424 and 6804,5370 and 6741,5316 and 6678 respectively. The 3D finite element model of the whole system and mesh surrounding crack tip region of the model are illustrated in Fig. 2.

Table 1 Material parameters of aluminum alloy

\begin{tabular}{lllll}
\hline $\mathrm{D}$ & $\mathrm{m}$ & $\mathrm{n}$ & $\sigma_{y}(\mathrm{MPa})$ & $k(\mathrm{MPa})$ \\
\hline 9164 & 0.93 & 0.0563 & 500 & 673.66 \\
\hline
\end{tabular}




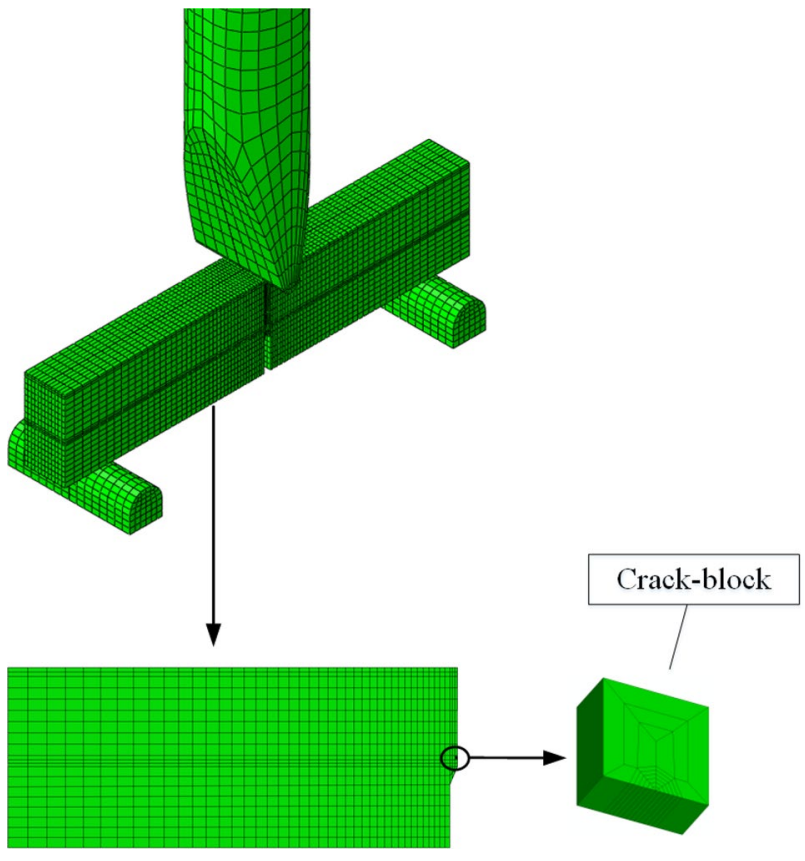

Fig. 2 Schematic diagram of three-dimensional finite element model with crack tip using crack-block technique

In order to explore the three-dimensional effects on DSIF finite element computation, this paper compared the computational results derived from two-dimensional and threedimensional model. The two-dimensional finite element model is constructed with the 4-node hexahedral element CPE4R in ABAQUS software. The whole model has 3019 elements and 3392 nodes. The two-dimensional finite element model is shown in Fig. 3.

\subsection{Experimental procedure}

The experimental procedure and data referred in this work are cited from papers $[2,8,20]$. The critical SIF of TPB

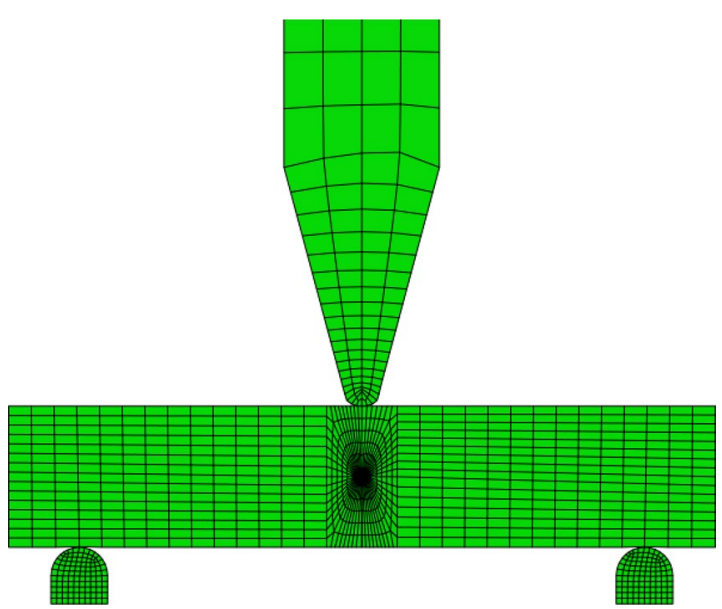

Fig. 3 Schematic diagram of two-dimensional finite element model specimen was derived from a modified SHPB device using the displacement of points at the crack mouth, related with the SIF employing a static relationship which can be applied to the dynamic case. The fracture time is obtained when the crack begins to propagate, which is measured by the gauges near the crack tip of the specimen. Then the critical SIF can be calculated.

\subsection{Validation of incident wave accuracy}

In order to verify the accuracy of the stress wave generated by the hitting between bullet and incident bar in this paper, the stress waves generated by numerical simulation is compared with the data obtained by attaching strain gauges on the middle surface of incident bar. The comparison results are illustrated in Fig. 4. As shown in Fig. 4, there are slight differences at the time axis between the results of twodimensional and three-dimensional computations and the experimental data. These differences may give rise to distinct wave velocities in two-dimensional and three-dimensional numerical simulations and experiments. In general, the results of two-dimensional and three-dimensional computations are in good agreement with the experimental data.

\section{Determination of stress intensity factor}

In the state of linear elasticity, Rice had proved that J-integral was the elastic strain energy release rate $G$. Therefore, we can get the relationship between J-integral and the stress intensity factor $K_{l}$.

$J=G_{l}=\frac{K_{l}^{2}}{E_{l}}$

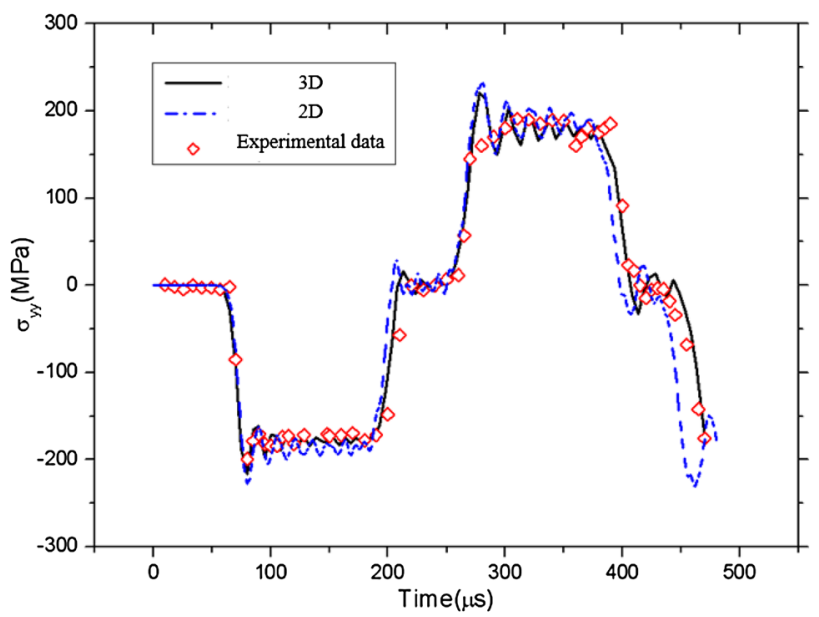

Fig. 4 Incident and reflected waves 
where $E_{l}=\left\{\begin{array}{ll}E & \text { (plane stress) } \\ \frac{E}{1-v^{2}} & \text { (plane strain) }\end{array}, \mathrm{E}\right.$ denotes the elastic modulus. $v$ represents the Poisson's ratio.

ABAQUS software directly outputs the computational values $J_{l}(t)$. When the $K$ dominant region is outside of the boundary of the inelastic region at the crack tip, the $K_{l}(t)$ may be determined in terms of Eq. (4).

If the sizes of three-point bending specimens meet Eqs. (5) and (6), the $\mathrm{K}$ dominant condition associated with small scale yielding may exist.

$B, a \geq 2.5\left(K_{l c} / \sigma_{y}\right)^{2}$

$b=W-a \geq 2.5\left(K_{l c} / \sigma_{y}\right)^{2}$

where $B$ represents thickness of the specimen, $W$ denotes width of the specimen, $b$ is width of the specimen ligament. Thickness of the specimen $B$ is $10 \mathrm{~mm}$, which is larger than the minimum thickness $B_{\text {min }}=5.9 \mathrm{~mm}$ prescribed in the standard requirements.

\section{Local stress fracture criterion}

The dynamic stress intensity factor $K_{l d}$ of the material can be obtained as long as the crack initiation time is determined in terms of the stress intensity factor time history. The local stress fracture criterion RKR reported by Ritchie et al. [21] is adopted to determine the initiation time $t_{f}$ using numerical simulation. The RKR criterion proposes that the crack begins to propagate if the normal stress $\sigma_{y y}$ perpendicular to the crack surface at a certain distance $d_{c}$ ahead of the crack tip reaches a critical value $\sigma_{f}$. The parameters of critical stress $\sigma_{f}$ and critical distance $d_{c}$ depends only on the material and irrespective of strain rate effect. Different values of $d_{c}$ correspond to relevent values of $\sigma_{f}$. The different combinations of $\sigma_{f}$ and $d_{c}$ can be selected. This criterion is further employed by Wall et al. [22] in the three-dimensional numerical simulation for crack growth under dynamic loading. The RKR local stress fracture criteria is described in Fig. 5.

It is well known that crack initiation occurs in the middle part of crack front of the three-point bending specimen, where is mostly close to plane strain condition. Therefore, in this paper, a pair values of $d_{c}$ and $\sigma_{f}$ derived from the middle plane of crack front of the three-dimensional finite element model are adopted to estimate crack initiation times. The static fracture toughness value of the specimen material is $K_{l c}=24.2 \mathrm{MPa} \sqrt{\mathrm{m}}$ according to the testing program. Subsequently, a pair values of critical stress and critical distance data could be determined from finite

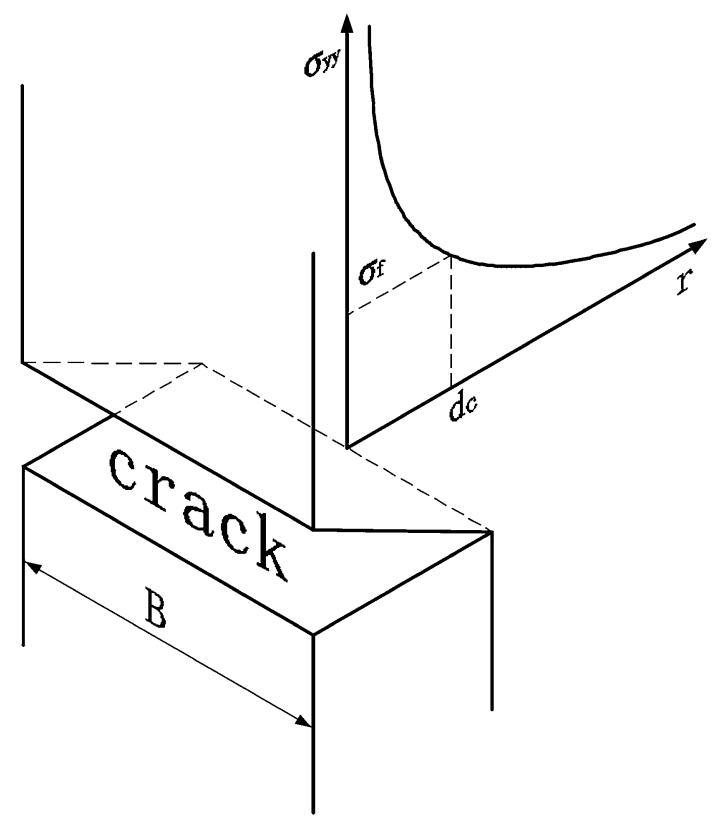

Fig. 5 RKR local stress fracture criterion

element simulations. The values of RKR criterion here are obtained in terms of the finite element computations. They are $d_{c}=11.5 \mu \mathrm{m}$ and $\sigma_{f}=2.468 \mathrm{GPa}, d_{c}=20.8 \mu \mathrm{m}$ and $\sigma_{f}=0.61 \mathrm{GPa}$ corresponding to three-dimensional and two-dimensional finite element models respectively.

\section{Results and discussion}

The finite element calculation results of specimens with three length-to-width ratio values are shown in Figs. 6 and 7. It can be seen from the figures that the stresses of 3D FEA simulations are a little larger than that of $2 D$ FEA simulations at the moments of crack initiation. That might be differences due to thickness effects for two type FEA models. According to the assumption of plane strain in the form of Eq. (4), the values of $J_{l}(t)$ obtained in the numerical simulation are converted into $K_{l}(t)$. Figure 8 gives the results of the time history $K_{l}(t)-t$ for specimens with different crack lengths ratios. The comparison results between the computational results of the three-dimensional and two-dimensional finite element models and the experimental data in literature [19] are list in Table 2. The the errors between results of the three-dimensional and two-dimensional finite element model and the test data are outlined.

As shown in Table 2, the dynamic fracture toughness values derived from numerical simulation and testing program range from 20.7 to $26.59 \mathrm{MPa} \sqrt{\mathrm{m}}$. The quasi-static fracture toughness value of the material is $24.2 \mathrm{MPa} \sqrt{\mathrm{m}}$. 
Fig. 6 Stress contours for specimens with different length-to-with ratio values (3D)
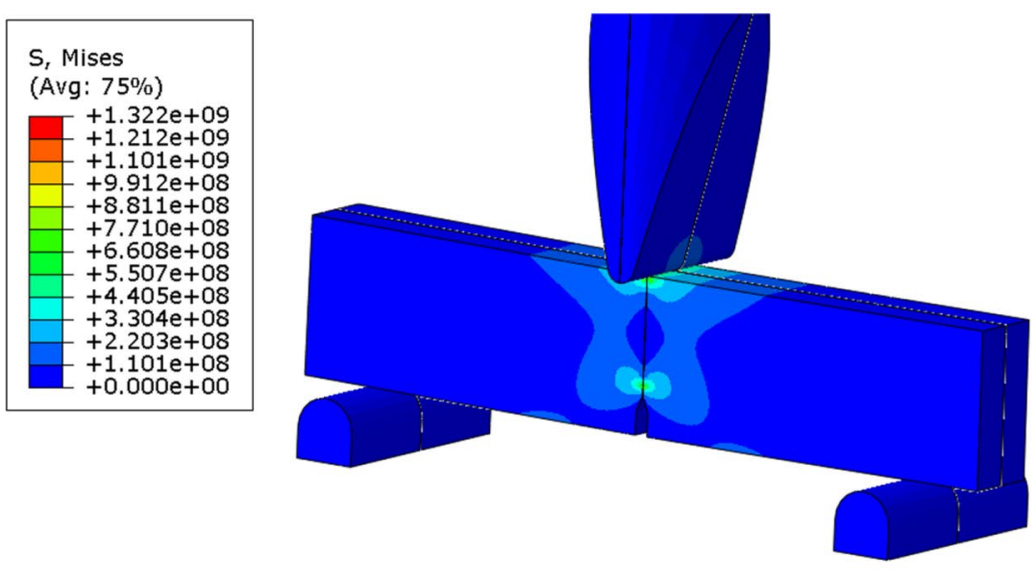

$\mathrm{a} / \mathrm{W}=0.3$
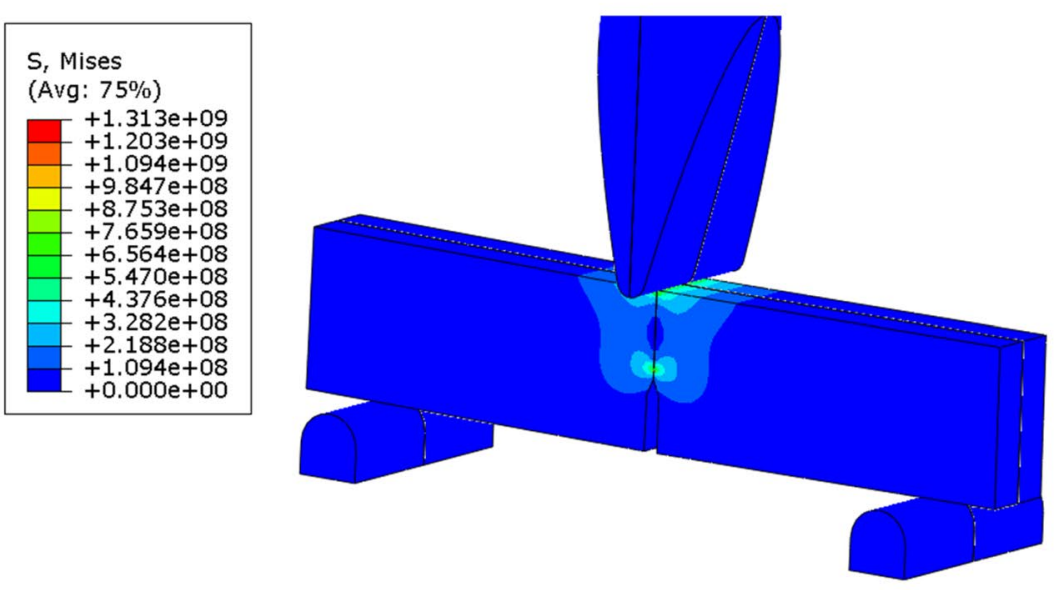

$\mathrm{a} / \mathrm{W}=0.5$

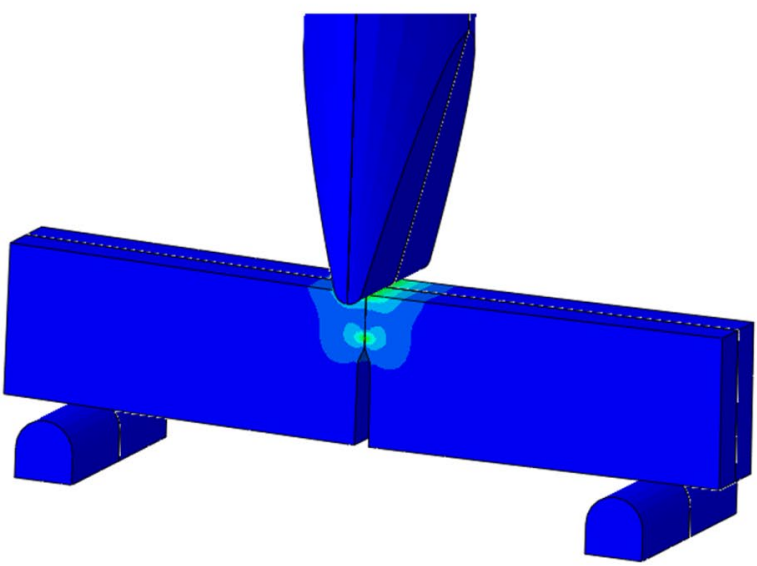

$\mathrm{a} / \mathrm{W}=0.7$
The dynamic fracture toughness value is close to the value under quasi-static condition for aluminum alloy. Dynamic fracture toughness value of this material is not obviously below the quasi-static value, which may be relative to the specified strain rate insensitivity of the material. The results of three-dimensional and two-dimensional computations in Table 2 demonstrate that when the specimens have the ratio $\mathrm{a} / \mathrm{w} 0.5$, the errors between the computational results and the test data are minimal. For different values of ratio $\mathrm{a} / \mathrm{w}$, the results of plane strain simulations are a little larger than the values derived from $3 \mathrm{~d}$ computations. The fracture initiation times determined from plane strain finite element simulations are smaller than the values derived from three-dimensional simulations. It reveals that there is a certain error for the plane strain finite element simulation. However, the deviation is acceptable. The results of 2D finite element computation has a bigger error using RKR criterion relative to $3 \mathrm{D}$ finite element simulation

\section{SN Applied Sciences}


Fig. 7 Stress contours for specimens with different length-to-with ratio values (2D)
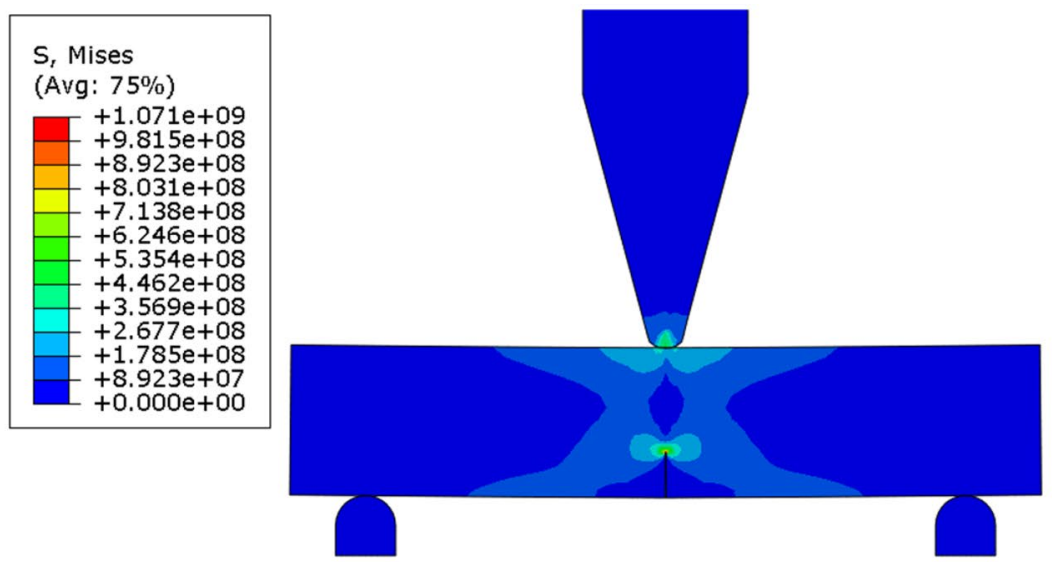

$\mathrm{a} / \mathrm{W}=0.3$
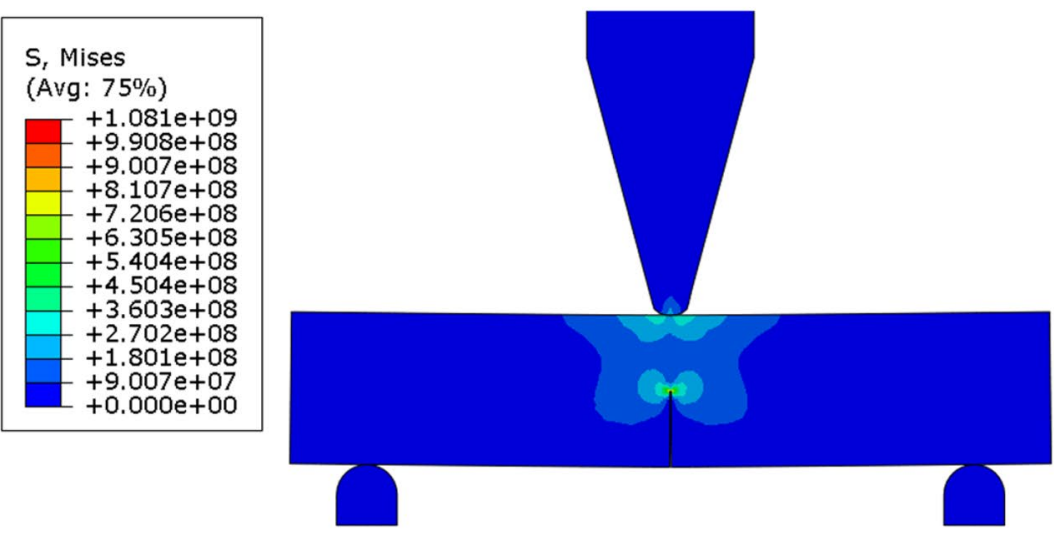

$\mathrm{a} / \mathrm{W}=0.5$
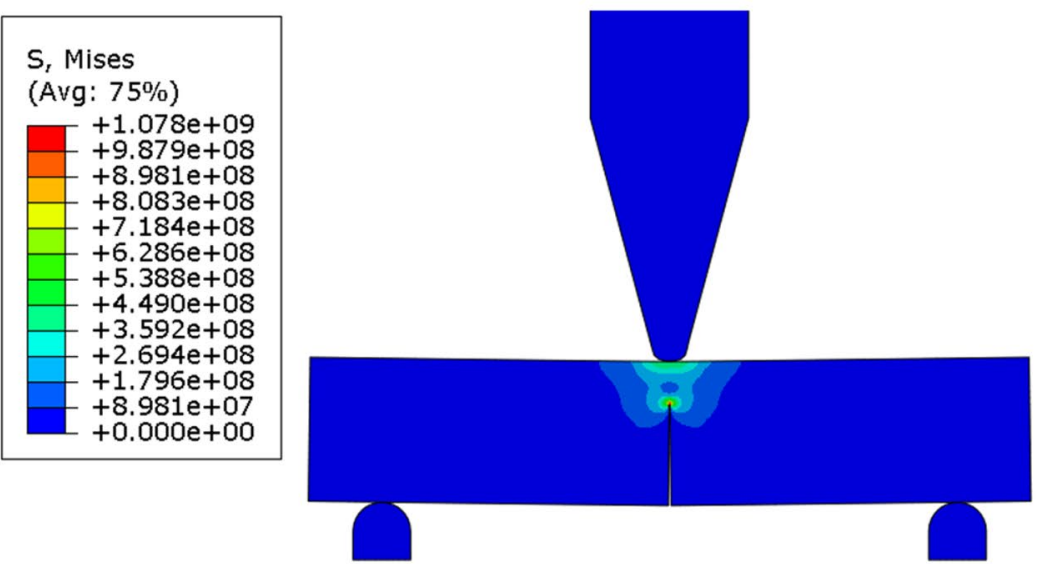

$\mathrm{a} / \mathrm{W}=0.7$ compared to experimental data. Therefore, the 3D finite element simulation results are more reliable than the 2D plane strain finite element based on the comparison above.

For shallow notched specimens $(a / W=0.3)$, the small scale yield stress field is achieved only at very low levels of loading $[2,23]$. Consequently, cleavage fracture toughness derived from the shallow notch specimens might demonstrate a strong geometry dependence. However, the TPB specimens containing large deep notches $(a / W=0.7)$ might exhibit some loss of constraint that affect the local stress field when large-scale plasticity is achieved. That is deformations imposed following development of a plastic hinge due to small remaining ligament length. 


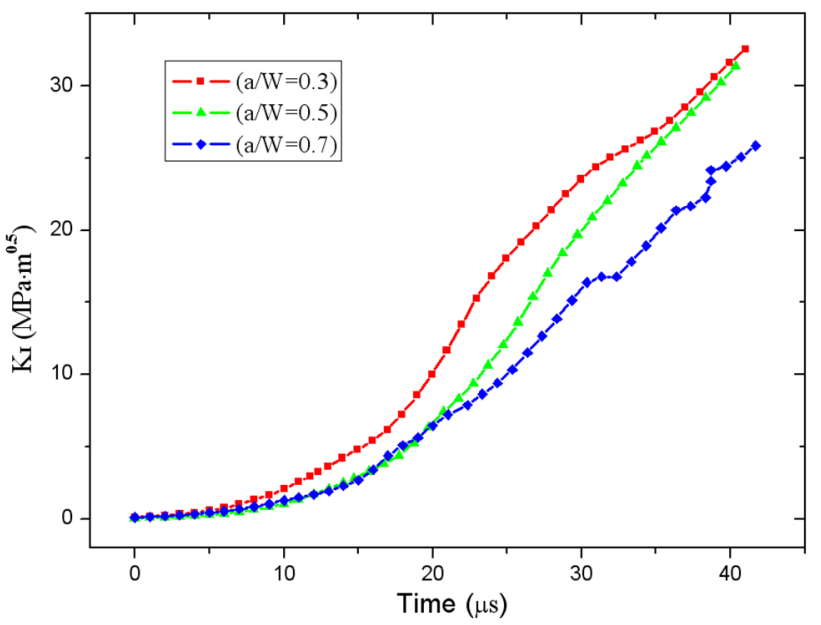

Fig. $8 K_{l}(t)-t$ curves for specimens with different ratio values

Specimens with ratio value of $\mathrm{a} / \mathrm{W}=0.5$ seems to maintain nearly plane-strain constraint condition with enough remaining ligament length compared to specimens other two length-to-width ratio values. The crack-tip stresses for these deeply notched TPB specimens closely approach small-scale yielding conditions. Fracture toughness data obtained with different crack ratio values should be independent of specimen geometry. It is elucidated in paper $[2,24]$ that the plastic hinge relationship is completely satisfied in case of $a / W=0.5$, which is considered as the standard a/W condition, for the specimens containing fatigue pre-cracks.

It is also shown that the fracture initiation time $t_{f}$ has a great influence on the determination of dynamic fracture toughness values. Therefore, the accurate determination of initiation time plays a key role for tests of the dynamic fracture toughness. During the test, the strain gauges pasted near the crack tip in the testing program may have different situations. It may render to a large dispersion for the testing data. The RKR local stress fracture criterion gives us another way to determine the initiation time for dynamic fracture tests. The research efforts in this paper eliminate that different combinations of $\sigma_{f}$ and $d_{c}$ can be utilized associated with RKR criterion. The error lies in the acceptable range. It is consistent with the research reported in Ref. [22]. However, the RKR criterion has its limitations. Some experimental results [21] exhibit that it is more suitable for cleavage fracture than elastoplastic fracture situations.

\section{Conclusion}

In this paper, the finite element software ABAQUS and the 3D fracture mechanics software ZENCRACK are utilized to conduct the three-dimensional and two-dimensional finite element simulations for SHPB tests using the threepoint bending specimen with different ratio $(a / W)$ values. ZENCRACK is perfomed to address the mesh of crack tips of three-dimensional finite element models. Therefore, the mesh around crack front of specimens in finite element models can keep consistent. The comparison of analyses between results of numerical simulations and testing programs exhibit that the dynamic fracture toughness values for specimens with different ratio values are close to each other. It reveals that the dynamic toughness value ia a principle property of the material. When the ratio value a/W of specimens is set to 0.5 , the $3 \mathrm{D}$ and $2 \mathrm{D}$ finite element numerical results have the smallest error compared to the experimental data which is taking as the benchmark. The 2D finite element computation using RKR criterion have a greater error than results of the 3D finite element numerical simulations. Different combinations of $\sigma_{f}$ and $d_{c}$ for RKR criterion can be selected. The corresponding deviations lie in the acceptable range for practical application.

\section{Compliance with ethical standards}

Conflict of interest On behalf of all authors, the corresponding author states that there is no conflict of interest.
Table 2 Results of numerical simulation and experiment

\begin{tabular}{|c|c|c|c|c|c|c|}
\hline \multirow[t]{2}{*}{ FEA model } & \multirow[t]{2}{*}{$\mathrm{a} / \mathrm{W}$} & \multicolumn{2}{|l|}{$t_{f}(\mu s)$} & \multicolumn{3}{|c|}{$K_{l d}(\mathrm{MPa} \sqrt{\mathrm{m}})$} \\
\hline & & Simulation & Experiment & Simulation & Experiment & Error (\%) \\
\hline $3 \mathrm{D}$ & 0.3 & 32 & 34 & 25.03 & 22.5 & 11.2 \\
\hline $2 \mathrm{D}$ & 0.3 & 24 & & 26.59 & & 18.2 \\
\hline $3 \mathrm{D}$ & 0.5 & 33 & 32 & 23.24 & 21.9 & 6.1 \\
\hline $2 \mathrm{D}$ & 0.5 & 26 & & 24.41 & & 11.4 \\
\hline $3 \mathrm{D}$ & 0.7 & 37 & 38 & 22.25 & 20.7 & 7.5 \\
\hline $2 \mathrm{D}$ & 0.7 & 31 & & 23.72 & & 14.6 \\
\hline
\end{tabular}




\section{References}

1. Ruiz C, Mines R (1985) The Hopkinson pressure bar: an alternative to the instrumented pendulum for Charpy test. Int J Fract 29(2):101-109

2. Bacon C, Farm J, Lataillade J (1994) Dynamic fracture toughness determined from load-point displacement. Exp Mech 20(1):217-223

3. Yokoyama T, Kishida K (1989) A novel impact three-point bend test method for determining dynamic fracture-initiation toughness. Exp Mech 29(2):188-194

4. Yokoyama T (1993) Determination of dynamic fracture-initiation toughness using a novel impact bend test procedure. J Press Vessel Technol 115(2):389-397

5. Li YL, Liu YY (1993) Calculation of DSIF of three point bending specimen using the method of DCOD. Explos Shock Waves 13(3):249-256

6. Liu RT, Zhang XX, Jiang FC, Ou GB (2000) Analysis of dynamic response of stress intensity factor of three-point bending specimen by using finite element method. J Harbin Eng Univ 21(3):49-51

7. Crouch B (1993) Finite element modeling of the three-point bend impact test. Comput Struct 48(4):167-173

8. Rubio L, Fernandez-Saez J, Navarro C (2003) Determination of dynamic fracture-initiation toughness using three-point bending tests in a modified Hopkinson pressure bar. Exp Mech 43:379-386

9. Narashiman R, Rosakis A (1990) Three-dimensional effects near a crack tip in a ductile three point bend specimen, part I: numerical investigations. J Appl Mech 2:121-134

10. Rokach IV (1996) Estimation of the three-dimensional effects for the impact fracture specimen. Arch Mech Eng 43(2-3):241-252

11. Nakamura T, Shih CF, Freund LB (1986) Analysis of a dynamically loaded three-point-bend ductile fracture specimen. Eng Fract Mech 25(3):323-339

12. Rosakis AJ, Ravi-Chandar K (1986) On crack-tip stress state: an experimental evaluation of three-dimensional effects. Int J Solids Struct 22(2):121-134

13. Motohiro N, Keizo K (1990) Numerical computation of dynamic stress intensity factor for impact fracture toughness test. Eng Fract Mech 36(3):515-522

14. Javed RA, Zhu SF, Guo CH et al (2014) Numerical investigation of the stress wave propagation in the incident bar and the specimen. Appl Mech Mater 602-605:98-101
15. Javed RA, Zhu SF, Guo CH et al (2015) Analyzing stress wave propagation in a hollow bar loaded three-point bend fracture test using numerical methods. Appl Mech Mater 782:9

16. ZENCRACK (2012) User's manuals, version 7.7, ZenTech

17. ABAQUS/Standard (2012) User's Manuals, Version 6.8, Hibbitt, Karlsson\&Sorensen, Inc

18. ASTM E1820-01 (2005) Standard test method for measurement of fracture toughness, Annual book of ASTM standards [S]. American Society for Testing and Materials

19. Loya JA, Fernandez-Saez J (2008) Three-dimensional effects on the dynamic fracture determination of Al 7075-T651 using TPB specimens. Int J Solids Struct 5:2203-2219

20. Loya JA, Fernandez-Saez J (2007) Dynamic fracture-initiation toughness ermination of Al 7075-T651 aluminum alloy. J Test Eval 25(1):1-6

21. Ritchie RO, Knott JF, Rice JR (1973) On the relationship between critical tensile stress and fracture toughness in mild steel. J Mech Phys Solids 21:395-410

22. Wall O (2002) Numerical modeling of fracture initiation in large steel specimens at impact. Eng Fract Mech 69:851-863

23. Dodds RH, Anderson TL, Kirk MT (1991) A framework to correlate a/W ratio effects on elastic-plastic fracture toughness $\left(J_{c}\right)$. Int $J$ Fract 48(1):1-22

24. Kawabata T, Tagawa T, Kayamori Y et al (2017) Plastic deformation behavior in SEB specimens with various crack length to width ratios. Eng Fract Mech 178:301-317

25. Kuntiyawichai K, Burdekin FM (2003) Engineering assessment of cracked structures subjected to dynamic loads using fracture mechanics assessment. Eng Fract Mech 73:1991-2014

26. Loya JA, Fernandez-Saez J (2007) Effect of the thickness, initial crack length and impact velocity on fracture dynamic initiation toughness of aluminum alloy. J Test Eval 35(1):25-30

27. Li ZA (1994) Pressure vessel fracture mechanics and defect assessment. Dalian: Dalian University of Technology Press, pp 73-76 (in Chinese)

Publisher's Note Springer Nature remains neutral with regard to jurisdictional claims in published maps and institutional affiliations. 